\title{
Blood pressure and age-related GFR decline in the general population
}

Bjørn O. Eriksen ${ }^{1,3^{*}} \mathbb{D}$, Vidar T. N. Stefansson ${ }^{1}$, Trond G. Jenssen ${ }^{1,4}$, Ulla D. Mathisen ${ }^{1,3}$, Jørgen Schei ${ }^{1}$, Marit D. Solbu ${ }^{1,3}$, Tom Wilsgaard ${ }^{2}$ and Toralf Melsom ${ }^{1,3}$

\begin{abstract}
Background: Hypertension is one of the most important causes of end-stage renal disease, but it is unclear whether elevated blood pressure (BP) also accelerates the gradual decline in the glomerular filtration rate (GFR) seen in the general population with increasing age. The reason may be that most studies have considered only baseline BP and not the effects of changes in BP, antihypertensive treatment and other determinants of GFR during follow-up. Additionally, the use of GFR estimated from creatinine or cystatin C instead of measurements of GFR may have biased the results because of influence from non-GFR related confounders. We studied the relationship between BP and GFR decline using time-varying variables in a cohort representative of the general population using measurements of GFR as iohexol clearance.
\end{abstract}

Methods: We included 1594 subjects aged 50 to 62 years without baseline diabetes, kidney-, or cardiovascular disease in the Renal lohexol-clearance Survey in Tromsø 6 (RENIS-T6). GFR, BP, antihypertensive medication and all adjustment variables were ascertained at baseline, and at follow-up after a median observation time of 5.6 years in 1299 persons (81\%). The relationship between GFR decline and BP was analyzed in linear mixed models.

Results: The mean (standard deviation) GFR decline rate was $0.95(2.23) \mathrm{mL} / \mathrm{min} /$ year. The percentage of persons with hypertension (systolic BP $\geq 140 \mathrm{mmHg}$, diastolic BP $\geq 90 \mathrm{mmHg}$ or antihypertensive medication) increased from 42 to $52 \%$ between baseline and follow-up. In multivariable adjusted linear mixed models using time-varying independent variables measured at baseline and follow-up, higher systolic and diastolic BP were associated with slower GFR decline rates by 0.10 and $0.20 \mathrm{~mL} / \mathrm{min} /$ year/10 $\mathrm{mmHg}$, respectively $(p<0.05)$. The association was stronger in persons on antihypertensive medication than in others $(p<0.05$ for the interaction between BP and antihypertensive medication).

Conclusions: In the medium-term, elevated BP is not associated with accelerated GFR decline in the general middle-aged population. In persons using antihypertensive medication, elevated BP is associated with a paradoxical slower GFR decline. Studies with even longer observation periods are needed to evaluate the ultimate effect of BP on kidney function.

Keywords: Age, Cardiovascular, Chronic renal failure, Elderly, Epidemiology, Hypertension

\footnotetext{
* Correspondence: bjorn.odvar.eriksen@unn.no

${ }^{1}$ Metabolic and Renal Research Group, UiT The Arctic University of Norway,

Tromsø, Norway

${ }^{3}$ Section of Nephrology, University Hospital of North Norway, Tromsø 9038,

Norway

Full list of author information is available at the end of the article
}

(c) The Author(s). 2017 Open Access This article is distributed under the terms of the Creative Commons Attribution 4.0 International License (http://creativecommons.org/licenses/by/4.0/), which permits unrestricted use, distribution, and reproduction in any medium, provided you give appropriate credit to the original author(s) and the source, provide a link to the Creative Commons license, and indicate if changes were made. The Creative Commons Public Domain Dedication waiver (http://creativecommons.org/publicdomain/zero/1.0/) applies to the data made available in this article, unless otherwise stated. 


\section{Background}

Hypertension is one of the most important causes of endstage renal disease [1-6]. However, it is not clear whether hypertension also contributes to the gradual loss of kidney function seen in the general population with increasing age. The age-related decline in glomerular filtration rate (GFR) is the most important predisposing cause of chronic kidney disease (CKD) in old age, which affects $70 \%$ at eighty years of age [7]. Several observational studies have found an association between baseline blood pressure (BP) and subsequent GFR decline or incident CKD, [8-14]. but there are also studies that have shown no relationship or even a higher GFR [15-20]. In a recent meta-analysis of randomized controlled trials including 44,389 participants, intensified antihypertensive treatment had no statistically significant effect on the risk of end-stage renal disease [21]. Except in patients with diabetes or CKD, there is currently no evidence from randomized controlled trials that antihypertensive treatment or intensified antihypertensive treatment lowers the risk of kidney dysfunction [22-25].

There are several possible explanations for the divergent results of observational studies. One important explanation could be that the great majority of these investigations have studied GFR decline as an effect of BP and antihypertensive treatment at baseline. Since both BP and treatment are dynamic parameters, they will change during follow-up and exert a variable influence on GFR. Because the effect of BP on GFR is commonly believed to be continuous and not limited to a one-time baseline event, this approach may give a distorted picture of the relationship between them. To our knowledge, no previous study of age-related GFR decline in the general population has considered this issue. Additionally, previous studies have relied on GFR estimated from creatinine or cystatin $C$ instead of actual measurements of GFR. These estimates are known to be influenced by several non-GFR factors that may have biased the results [26-28].

We have measured GFR as iohexol clearance in the Renal Iohexol-clearance Survey in Troms $\varnothing 6$ (RENIS-T6) and again in the RENIS Follow-up Study (RENIS-FU) after a median observation time of 5.6 years. Iohexol clearance is recognized as a precise method for measuring GFR [29]. As far as we know, this is the only study of agerelated GFR decline using GFR measurements. In a previous analysis, we found no association between baseline BP and GFR decline [30]. In the present study, we investigated the relationship between the GFR decline rate and $\mathrm{BP}$ and antihypertensive treatment ascertained as timevarying variables at both baseline and follow-up.

\section{Methods}

\section{Study population}

This study is a follow-up of RENIS-T6 which measured baseline iohexol-clearance in 1627 people between 50 and 62 years of age between 2007 and 2009. We included a representative sample of subjects from the general population without self-reported kidney disease, myocardial infarction, stroke or diabetes from the municipality of Tromsø in Northern Norway, as previously described in detail [31]. In the present study, we excluded 33 subjects who satisfied biochemical criteria for diabetes (fasting glucose $\geq 7.0 \mathrm{mmol} / \mathrm{L}$ and/or hemoglobin A1c $\geq 6.5 \%$ ) at baseline, leaving 1594 subjects. Ten subjects with missing data for baseline hemoglobin A1c who all had fasting glucose $<7.0 \mathrm{mmol} / \mathrm{L}$, were not excluded. Follow-up measurements of GFR in RENIS-FU were performed between September 2013 and January 2015. All the participants of the baseline study were invited except for 23 subjects who had died and 7 who had suffered a possible delayed allergic reaction to iohexol, leading to 1564 total people eligible (Fig. 1). A random sample of $5 \%$ was invited to a repeated follow-up GFR measurement to obtain a group of subjects with three GFR measurements, which is necessary for analysis with a linear mixed regression model with random intercept and slope and an unstructured covariance matrix [32].

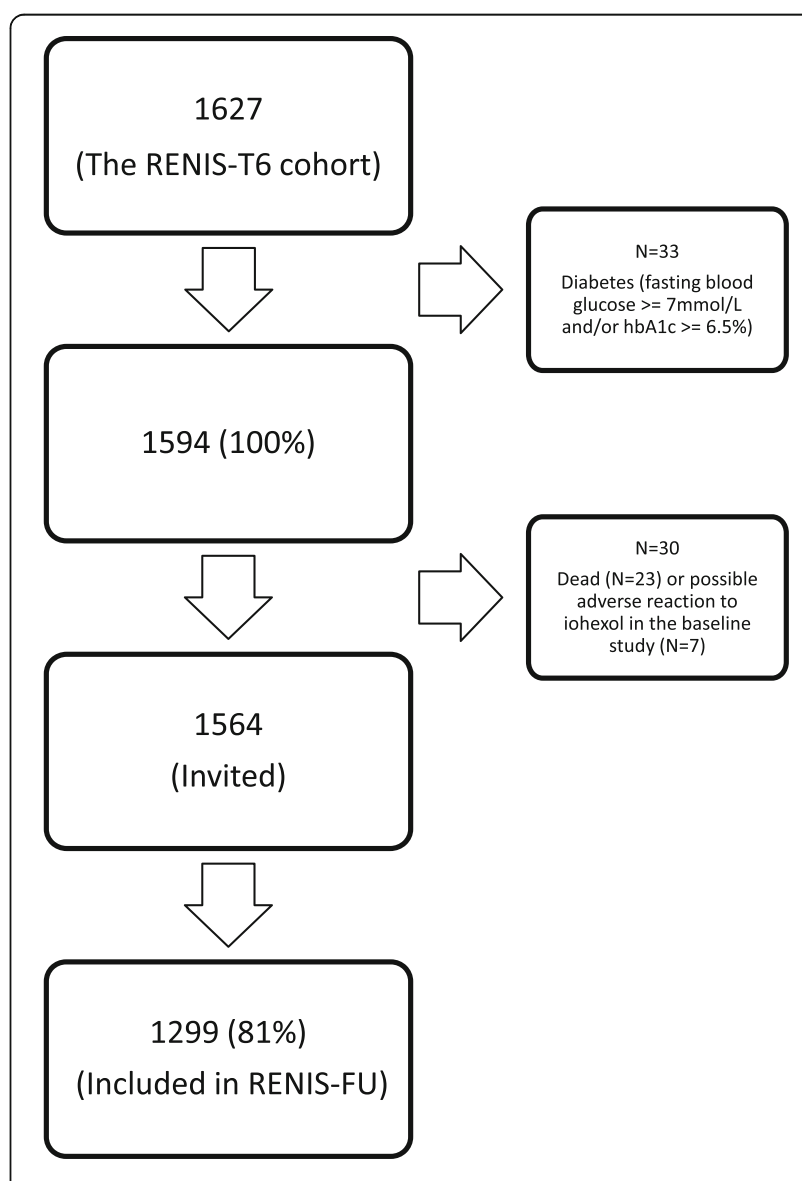

Fig. 1 Inclusion of subjects in the RENIS follow-up study (RENIS-FU) 
This study complied with the Declaration of Helsinki and was approved by the Norwegian Data Inspectorate and the Regional Committee for Medical and Health Research Ethics of North Norway. All subjects provided written consent. All procedures were in accordance with institutional guidelines.

\section{Data}

Both RENIS-T6 and RENIS-FU were conducted in the Clinical Research Unit at the University Hospital of North Norway. A health questionnaire with questions about alcohol and tobacco use and all current medications was administered on both occasions. Tobacco use was coded as the number of cigarettes currently smoked daily. Alcohol use was coded as 1 for the use of alcohol more than once a week and 0 otherwise.

\section{Measurements}

\section{lohexol clearance}

Baseline and follow-up GFR were measured using single-sample plasma clearance of iohexol, which has been validated against gold standard methods [33-36]. RENIS-FU used the same procedure as in the baseline RENIS-T6, which has previously been described in detail [30, 31].

A $6 \%$ random sample of blood samples from the baseline investigation previously frozen at $-80{ }^{\circ} \mathrm{C}$ were thawed and reanalyzed to adjust for a possible drift in the method between baseline and follow-up. The mean difference in the GFR between follow-up and baseline was $2.28 \mathrm{~mL} / \mathrm{min} / 1.73 \mathrm{~m}^{2}$. All baseline GFR measurements reported in this study were adjusted by adding this constant to the original measurements, as described previously [30].

A total of 87 subjects had a repeated follow-up measurement of GFR. The mean coefficient of variation (95\% confidence interval) for the intra-individual GFR variation was $4.2 \%$ (3.4-4.9\%) [30]. The repeated follow-up measurements was performed a median (interquartile range (IQR)) of 35 (22-49) days after the first.

\section{Blood pressure measurements}

Attended BP measurements were performed by trained study nurses in the seated position after 2 min rest using an automated device and the appropriate cuff size (model UA 799; A\&D, Tokyo, Japan). BP was measured three times with $1 \mathrm{~min}$ between measurements. The average of the second and the third measurement was used in the analyses. Hypertension was defined as systolic BP $(\mathrm{SBP}) \geq 140 \mathrm{mmHg}$, diastolic $\mathrm{BP}(\mathrm{DBP}) \geq 90 \mathrm{mmHg}$ or the use of antihypertensive medication. Mean pulse pressure (PP) was defined as SBP minus DBP and mean arterial pressure (MAP) as DBP plus one-third of the PP.

\section{Other measurements}

Fasting serum glucose, creatinine, cystatin $\mathrm{C}$, triglycerides, and LDL- and HDL-cholesterol, hemoglobin A1C and the urine albumin-creatinine ratio (ACR) were measured with standard methods as described previously $[37,38]$. Serum creatinine was measured using an enzymatic assay standardized to the isotope dilution mass spectroscopy method (CREA Plus, Roche Diagnostics, $\mathrm{GmbH}$, Mannheim, Germany). Cystatin $\mathrm{C}$ was measured by a particle-enhanced turbidimetric immunoassay (Gentian, Moss, Norway) and calibrated to the international reference ERM-DA471/IFCC as previously described [39]. Estimated GFR (eGFR) was calculated from creatinine or cystatin $C$ using the Chronic Kidney Disease Epidemiology Collaboration equations ( $\mathrm{eGFR}_{\text {crea }}$ and $\left.\mathrm{eGFR}_{\text {cys }}\right)$ [40].

\section{Statistical methods}

Mean (standard deviation (SD)) or median (IQR) for skewed variables were used for descriptive statistics. Differences between baseline and follow-up were tested with the paired $t$-test or Wilcoxon signed-rank test for continuous variables and McNemar's test for paired dichotomous variables.

The GFR measurements were analyzed in linear mixed models with random intercept and slope [32, 41]. All of the subjects included in the baseline RENIS cohort were included in the linear mixed regression analyses regardless of whether they were examined at follow-up because linear mixed models allow for missing observations at one or more points in time $[41,42]$. The subjects had from one to three GFR measurements: baseline $(n=1594)$, follow-up $(n=1299)$ and/or repeated follow-up $(n=87)$. Absolute GFR in $\mathrm{mL} / \mathrm{min}$ was used as the dependent variable. Observation time from baseline was used as the independent time variable. Associations between the BP components (SBP, DBP, PP and MAP) and the rate of change in GFR were estimated by including two-way interaction terms between the BP variable in question and the time variable. Separate regression analyses were performed for each BP component. The linear mixed regression used time-varying values measured at both baseline and follow-up for all the independent variables, including BP components, antihypertensive treatment and adjustment variables.

The linear mixed regression analyses were adjusted for baseline age, sex and the following two sets of timevarying adjustment variables: Model 1 (body weight; height; individual dichotomous variables for the use of ACE-inhibitors, A2-receptor blockers, beta-blockers, calcium-blockers, diuretics and other antihypertensives) and model 2 (same variables as model 1 and also including LDL-cholesterol, HDL-cholesterol, fasting triglycerides, fasting glucose, ACR, pulse frequency, number of cigarettes currently smoked, and a dichotomous variable for the alcohol use). 
Non-linear effects of the BP components on the GFR rate of change were explored by including seconddegree fractional polynomial transformations of the BP components in the interactions with time in the linear mixed regression models [43].

Subjects with missing data for alcohol use $(n=6)$, ACR $(n=5)$ or triglycerides $(n=4)$ at baseline, and one subject with missing data for alcohol use at follow-up were excluded from the analyses. There were no missing data for the other independent variables or for GFR.

The same linear mixed regression analyses as described above were performed with change in estimated GFR assessed by $\mathrm{eGFR}_{\text {crea }}$ or $\mathrm{eGFR}_{\text {cys }}$ as the dependent variables. Statistical significance was set at 0.05 . All of the statistical analyses were performed in STATA/MP 13.1 (www.stata.com).

\section{Results}

A total of 1299 (81\%) of the 1594 participants in the baseline cohort were investigated at follow-up after a median (IQR) observation time of 5.63 years (5.23-6.03) (Fig. 1). Most variables changed between baseline and follow-up (Table 1). The percentage of subjects with hypertension increased from 42 to 52 and the percentage of subjects receiving antihypertensives from 18 to 31 between baseline and follow-up. There was a slight increase in SBP and a slight reduction in DBP $(p<0.05)$. Except for the percentage of current smokers (18 vs. 28, $p<0.05)$, there were only small differences in baseline characteristics between those included and those lost to follow-up, as reported previously [30].

The unadjusted mean (SD) rate of change for the absolute GFR in the study period was $-0.95(2.23) \mathrm{mL} / \mathrm{min} /$ year. A negative change signifies a decline in GFR.

The absence of associations between baseline BP components and the GFR decline rate has been reported previously [30]. When analyzing time-varying BP with adjustment for independent variables measured at both baseline and follow-up; SBP, DBP and MAP, but not PP, were positively associated with GFR change in separate models, indicating slower GFR decline for higher BP values $(p<0.05)$ (Table 2), i.e. that lowering of BP was associated with a steeper GFR decline. Because timevarying independent variables for antihypertensive medication were used, these associations were independent of both the antihypertensive medication and changes in medication use between baseline and follow-up.

There were no statistically significant non-linear relationships between the BP components and GFR rate of change.

There were statistically significant interactions between a dichotomous time-varying variable for antihypertensive treatment (yes/no) and SBP, DBP, and MAP respectively in the fully adjusted models in Table $2(p<0.001)$. The interactions indicate that the associations between GFR decline and SBP, DBP and MAP were stronger when combined with antihypertensive medication (Fig. 2).

We performed subgroup analyses for persons with hypertension at baseline and/or follow-up, for persons with normotension at both baseline and follow-up, for persons without self-reported heart disease, for persons without albuminuria (ACR less than $1.92 \mathrm{mg} / \mathrm{mmol}$ for men and $2.83 \mathrm{mg} / \mathrm{mmol}$ for women) and for persons with GFR greater than $60 \mathrm{ml} / \mathrm{min} / 1.73 \mathrm{~m}^{2}$ (Additional file 1: Tables S1 and S2). The results were numerically similar to the main results in Table 2, but not statistically significant for SBP, DBP and MAP in the normotensive subgroup.

The associations between BP components and GFR decline assessed by body-surface adjusted GFR (GFR $\mathrm{GSA}_{\mathrm{BS}}$ ) and estimated GFR based on either creatinine or cystatin $\mathrm{C}\left(\mathrm{eGFR}\right.$ crea and eGFR $\left.\mathrm{cys}_{\text {cs }}\right)$ were analyzed (Additional file 1 : Table S3). The same models as in Table 2 were used. There was no statistically significant relationship between any of the BP components and eGFR $\mathrm{crea}_{\text {or }}$ oGFR $\mathrm{Gyy}_{\text {. The }}$ results for $\mathrm{GFR}_{\mathrm{BSA}}$ were similar to those for absolute GFR in Table 2.

The regression models in Table 2 were re-analyzed with the mean of baseline and follow-up values substituted for the time-varying independent variables as predictors of the GFR decline slope. The results were essentially the same as in Table 2 (Additional file 1: Table S4).

\section{Discussion}

The results of this investigation do not support the hypothesis that elevated BP causes accelerated age-related GFR decline in the general population during almost 6 years of follow-up (Table 2). On the contrary, the analyses indicate an association of higher SBP, DBP and MAP with a paradoxical slower GFR decline, i.e. that improved BP was associated with a steeper decline. There were statistically significant interactions between the $\mathrm{BP}$ components and antihypertensive treatment, so that the associations between BP and GFR decline occurred primarily in patients treated with antihypertensive agents (Fig. 2). The reason may be that GFR is more sensitive to $\mathrm{BP}$ changes in treated persons because longstanding hypertension or antihypertensive drugs interfere with the autoregulation of glomerular blood flow $[44,45]$. This makes GFR more sensitive to changes in $\mathrm{BP}$, which manifested as a steeper GFR decline with intensified BP treatment in our population.

In randomized controlled trials of antihypertensive drugs in CKD patients, an initial drop in GFR is commonly observed when treatment is started, followed by a subsequent slower decline [46, 47]. This finding has been interpreted as a beneficial effect of reducing an abnormally high GFR, so-called hyperfiltration [48]. 
Table 1 Study population characteristics at baseline and follow-up. The RENIS-FU study

\begin{tabular}{|c|c|c|c|}
\hline & Baseline & Follow-up & $P$-value for difference ${ }^{a}$ \\
\hline $\mathrm{N}(\%)$ & 1594 & 1299 & \\
\hline Male gender, $\mathrm{n}(\%)$ & 781 (49\%) & $643(49 \%)$ & \\
\hline Age, years & $58.1(3.8)$ & $63.6(4.0)$ & \\
\hline Body mass index, kg/m2 & $27.2(4.0)$ & $27.1(4.0)$ & 0.59 \\
\hline Hypertension ${ }^{\mathrm{b}}, \mathrm{n}(\%)$ & $674(42 \%)$ & $672(52 \%)$ & $<0.001$ \\
\hline Systolic $\mathrm{BP}, \mathrm{mmHg}$ & $129.4(17.5)$ & $130.5(16.9)$ & 0.001 \\
\hline Diastolic BP, mmHg & $83.4(9.8)$ & $81.9(9.3)$ & $<0.001$ \\
\hline Pulse pressure, $\mathrm{mmHg}$ & $46.1(11.4)$ & $48.6(12.2)$ & $<0.001$ \\
\hline Mean arterial $\mathrm{BP}, \mathrm{mmHg}$ & $98.7(11.7)$ & $98.1(10.9)$ & 0.08 \\
\hline Pulse frequency, beats/min & $66.6(9.8)$ & $64.5(9.2)$ & $<0.001$ \\
\hline Antihypertensive medication, $\mathrm{n}(\%)$ & $289(18 \%)$ & $405(31 \%)$ & $<0.001$ \\
\hline ACE inhibitor, $\mathrm{n}(\%)$ & $28(1.8 \%)$ & $48(3.7 \%)$ & $<0.001$ \\
\hline A2 blocker, n (\%) & $132(8.3 \%)$ & $201(15.5 \%)$ & $<0.001$ \\
\hline Betablocker, n (\%) & $67(4.2 \%)$ & $93(7.2 \%)$ & $<0.001$ \\
\hline Calcium blocker, n (\%) & $80(5.0 \%)$ & $126(9.7 \%)$ & $<0.001$ \\
\hline Diuretic, n (\%) & $140(8.8 \%)$ & $203(15.6 \%)$ & $<0.001$ \\
\hline Other antihypertenives, n (\%) & $1(0.1 \%)$ & $5(0.4 \%)$ & 0.06 \\
\hline Current smoker, n (\%) & $322(20 \%)$ & $173(13 \%)$ & $<0.001$ \\
\hline Use of alcohol more than 2-4 times a month, $n(\%)$ & $434(27 \%)$ & $431(33 \%)$ & 0.01 \\
\hline LDL cholesterol, mmol/L & $3.67(0.86)$ & $3.58(0.90)$ & $<0.001$ \\
\hline HDL cholesterol, mmol/L & $1.54(0.42)$ & $1.63(0.46)$ & $<0.001$ \\
\hline Fasting triglycerides, $\mathrm{mmol} / \mathrm{L}$ & 1.00 (0.80 to 1.50$)$ & 1.00 (0.80 to 1.30$)$ & 0.12 \\
\hline Fasting glucose, $\mathrm{mmol} / \mathrm{L}$ & $5.30(5.00$ to 5.60$)$ & $5.40(5.10$ to 5.80$)$ & $<0.001$ \\
\hline Urinary albumin-creatinine ratio, $\mathrm{mg} / \mathrm{mmol}$ & 0.23 (0.10 to 0.54$)$ & 0.34 (0.10 to 0.58 ) & $<0.001$ \\
\hline Absolute GFR, $\mathrm{mL} / \mathrm{min}$ & $103.8(19.9)$ & $98.2(19.8)$ & $<0.001$ \\
\hline $\mathrm{GFR}, \mathrm{mL} / \mathrm{min} / 1.73 \mathrm{~m} 2$ & $93.8(14.3)$ & $88.9(14.5)$ & $<0.001$ \\
\hline
\end{tabular}

Estimates are given as mean (standard deviation), median (interquartile range) or percent

Abbreviations: RENIS-FU Study the Renal lohexol-clearance Survey Follow-up Study, HDL high-density lipoprotein, $L D L$ low-density lipoprotein, BP blood pressure, GFR glomerular filtration rate

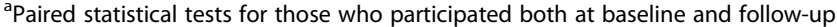

${ }^{\mathrm{b}}$ Systolic BP $>=140$, diastolic BP $>=90$ or antihypertensive medication

Table 2 The associations between time-varying blood pressure and GFR change rates in linear mixed regression analyses. The RENIS-FU study

\begin{tabular}{|c|c|c|c|c|c|c|}
\hline \multirow[t]{2}{*}{ BP component } & \multicolumn{3}{|l|}{ Model $1^{\mathrm{a}}$} & \multicolumn{3}{|l|}{ Model $2^{b}$} \\
\hline & Beta (mL/min/year) & 95\% confidence interval & $P$-value & Beta $(\mathrm{mL} / \mathrm{min} /$ year) & 95\% confidence interval & $P$-value \\
\hline Systolic BP per $10 \mathrm{mmHg}$ & 0.09 & 0.02 to 0.17 & 0.02 & $0.10^{\ddagger}$ & 0.02 to 0.18 & 0.02 \\
\hline Diastolic BP per $10 \mathrm{mmHg}$ & 0.16 & 0.02 to 0.30 & 0.03 & $0.20^{5}$ & 0.05 to 0.34 & 0.01 \\
\hline Pulse pressure per $10 \mathrm{mmHg}$ & 0.08 & -0.03 to 0.19 & 0.15 & 0.07 & -0.04 to 0.18 & 0.21 \\
\hline Mean arterial pressure per $10 \mathrm{mmHg}$ & 0.15 & 0.03 to 0.27 & 0.01 & $0.17^{\|}$ & 0.05 to 0.30 & 0.007 \\
\hline
\end{tabular}

Each horizontal section in the table corresponds to one linear mixed regression model. Negative coefficients indicate a steeper GFR decline; positive coefficients a slower decline. The models used time-varying independent variables measured at both baseline and follow-up

Abbreviations: RENIS-FU Study the Renal lohexol-clearance Survey Follow-up Study, BP blood pressure

${ }^{a}$ Model 1 adjusted for age; sex; body weight; height; individual dichotomous variables for the use of ACE-inhibitors, A2-receptor blockers, beta-blockers, calcium-blockers, diuretics and other antihypertensives

${ }^{\mathrm{b}}$ Adjusted as model 1 and in addition LDL-cholesterol, HDL-cholesterol, fasting triglycerides, fasting glucose, urinary ACR, pulse frequency, number of cigarettes currently smoked, a dichotomous variable for the weekly use of alcohol or not

${ }^{\ddagger} P<0.001$ for the interaction between systolic BP and the use of any antihypertensive medication. Beta $=0.01 \mathrm{without}$ and $0.33 \mathrm{~mL} / \mathrm{min} / \mathrm{year} / 10 \mathrm{mmHg}$ with antihypertensive medication

${ }^{\S} P=0.001$ for the interaction between diastolic BP and the use of any antihypertensive medication. Beta $=0.09 \mathrm{without}$ and $0.42 \mathrm{~mL} / \mathrm{min} / \mathrm{year} / 10 \mathrm{mmHg}$ with antihypertensive medication

$\| P<0.001$ for the interaction between mean arterial pressure and the use of any antihypertensive medication. Beta $=0.05 \mathrm{without}$ and $0.49 \mathrm{~mL} / \mathrm{min} / \mathrm{year} /$

$10 \mathrm{mmHg}$ with antihypertensive medication 


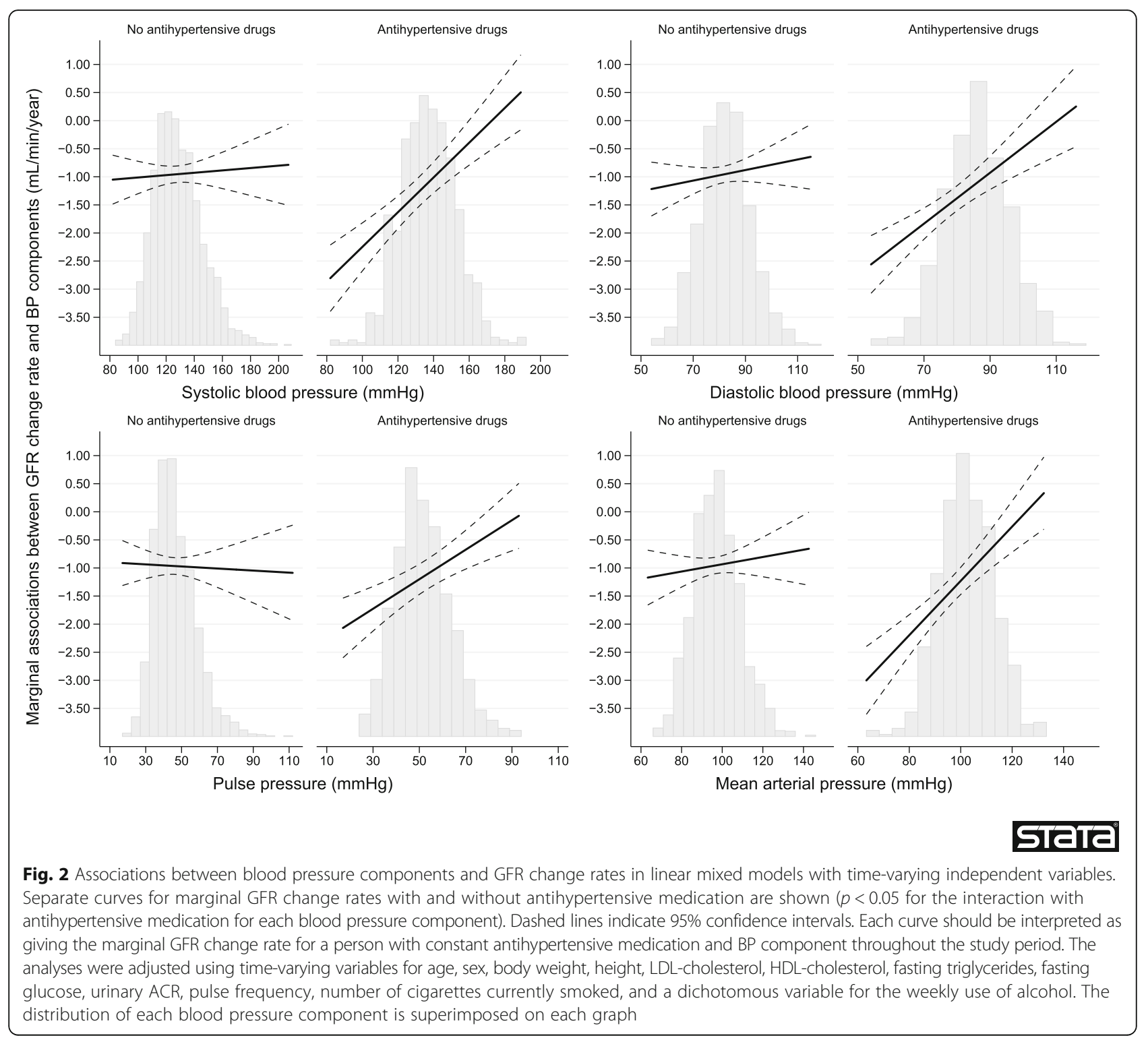

Hyperfiltration is thought to be the first step in a sequence of events leading to reduced GFR and CKD [49]. However, there is also evidence of a longer-term drop in estimated GFR after intensive antihypertensive treatment, recently seen in two randomized trials with median follow-up of three years [24, 25]. Although our study population differs in several respects from the patients in these studies, our results suggest that the phase of reduced GFR due to an improvement of hyperfiltration may last longer than previously thought. This may explain the lack of effect on renal endpoint in trials with follow-up ranging from 1 to 7 years [22, 23].

To our knowledge, the present study is the first to assess the association between BP and GFR decline in the general population using measurements rather than estimates of GFR. Studies that have used serum creatinine, estimated GFR, or creatinine clearance have given mixed results $[8-14,50]$. We found no statistically significant associations between BP and the change rates of estimated GFR based on creatinine and/or cystatin C (Additional file 1: Table S3). The reason may have been the influence of non-GFR factors on creatinine and cystatin $\mathrm{C}$ or the low precision of estimated GFR in the normal range [26-28]. To our knowledge, only one previous study of GFR decline has used time-varying $\mathrm{BP}$ in a non-CKD population [51]. Vupputuri et al. found an association between increased time-varying $\mathrm{BP}$ and rapid GFR decline. However, the study was not populationbased, it used estimated GFR from creatinine and did not adjust for changes in antihypertensive medication. In the general population, we are not aware of any previous study that has adjusted for individual classes of 
antihypertensive medications or included time-varying adjustment variables. The considerable changes observed in both antihypertensive medication and hypertension status during the follow-up in our study underlines the importance of using statistical models that do not rely solely on baseline variables.

The finding of an association between higher BP and a slower GFR decline seems to be inconsistent with observational studies that have found hypertension a risk factor for both ESRD $[1,2,5]$. and less severe CKD [52-57]. One possible explanation is that additional genetic or environmental factors may lead to the development of progressive kidney disease in susceptible patients only. Another possibility is that renal hyperfiltration may be the first stage of hypertensive nephropathy, similar to the hyperfiltration phase of diabetic nephropathy. We measured whole kidney GFR which is a function of the total number of nephrons and single nephron GFR. Other studies have found a reduced nephron number in subjects with hypertension [58-60]. If we conservatively assume an average rate of age-related loss of nephrons in hypertensive subjects, a slower than average decline in whole kidney GFR implies an increasing single nephron GFR in the remaining nephrons. This means that our findings most likely reflect an elevated GFR or hyperfiltration at the single nephron level. Other studies have also found crosssectional associations between elevated BP and hyperfiltration both in hypertensive patients [15-18]. and in the general population [19].

Conditions with both low BP and low GFR, such as advanced heart failure and serious infections, could possibly confound the association between low BP and a faster GFR decline, but are unlikely to explain the findings in this relatively healthy, ambulatory cohort. Only subjects without cardiovascular disease at baseline were included, and an analysis after excluding subjects with self-reported heart disease at follow-up made essentially the same findings as in the main analysis (Additional file 1: Table S1). We rescheduled GFR measurements for subjects with acute infections.

The principal strength of the present study is the use of measured GFR rather than estimated GFR from creatinine or cystatin $C$. When we repeated the analyses with estimated GFR instead of iohexol clearance, the regression coefficients were attenuated and not statistically significant (Additional file 1: Table S3). We limited confounding from comorbid conditions by excluding subjects with diabetes or cardiovascular disease at baseline. Because a third GFR measurement was obtained from a random subset of subjects, state-of-the-art linear mixed models rather than ordinary linear regression could be used for the analyses [61].

The most important limitation of our investigation was that conclusions about causality cannot be drawn from an observational study. In particular, the use of time-varying variables in the regression analyses does not allow us to establish the temporal precedence of elevated $B P$ relative to a change in GFR decline, and can only demonstrate an association between these variables. The direction of causality is also uncertain, as subclinical renal damage has been suggested as a possible cause of primary hypertension [62]. In addition, the time varying variables were only ascertained at baseline and follow-up. More frequent measurements during follow-up would have given a more detailed picture of the relationship between BP and GFR and more precise estimates of effects, but would probably not have changed the overall conclusions or our study. Only middle-aged Caucasians were included and caution should be exercised when generalizing the results to other age groups and ethnic groups.

\section{Conclusions}

We conclude that higher BP is not associated with an accelerated mean age-related GFR decline in the general population, but that lower BP because of antihypertensive treatment is associated with a medium-term steeper GFR decline. This finding is still consistent with a longterm beneficial effect of antihypertensive treatment on GFR decline, but indicates that a possible long term slowing effect on the decline may be preceded by a phase of reduced hyperfiltration of longer duration than previously thought. This should be investigated in studies with longer follow-up and repeated measurements of GFR. In primary hypertension, randomized controlled trials of the effect of antihypertensive treatment on renal endpoints should employ substantially longer follow-up than in previous trials.

\section{Additional file}

Additional file 1: Four additional tables (Table S1-S4.) (DOCX 43 kb)

\section{Abbreviations}

ACR: Albumin creatinine ratio; BP: Blood pressure; CKD: Chronic kidney disease; DBP: Diastolic BP; eGFR: Estimated glomerular filtration rate; eGFR crea: eGFR based on serum creatinine; eGFR cys: $_{\text {s }}$ eGFR based on serum cystatin C; GFR: Glomerular filtration rate; GFRBSA: Body-surface adjusted GFR; IQR: Interquartile range; MAP: Mean arterial pressure; PP: Pulse pressure; RENIS-FU: RENIS Follow-up Study; RENIS-T6: Renal lohexol-clearance Survey in Tromsø 6; SBP: Systolic BP; SD: Standard deviation

\section{Acknowledgements}

We thank Britt-Ann Winther Eilertsen, Bjørg Skog Høgset and the staff at the Clinical Research Unit (University Hospital of North Norway) for assistance in planning the study, performing the procedures and collecting data. We also thank Harald Strand and the staff at the Department of Medical Biochemistry (University Hospital of North Norway) for performing the HPLC analyses of iohexol. We are grateful to all the participants in the RENIS cohort for making this study possible. 


\section{Funding}

RENIS-FU was funded by the Northern Norway Regional Health Authority, UiT The Arctic University of Norway and by a grant from Boehringer-Ingelheim. None of the sources of funding had any role in the design of the study or collection, analysis, or interpretation of data or in writing the manuscript.

\section{Availability of data and materials}

The datasets analysed during the current study are not publicly available due to ongoing publication projects, but are available from the corresponding author on reasonable request.

\section{Authors' contributions}

Conception or design of study: BOE, TM, TGJ, UDM, MDS. Analysis of data: BOE, TW. Acquisition and interpretation of data: BOE, VTNS, JS, UDM, TM, MDS, TW. Drafting the manuscript: BOE. Revising the manuscript critically for important intellectual content: VTNS, TGJ, UDM, JS, MDS, TW, TM. All authors read and approved the final manuscript. All authors agreed to be accountable for all aspects of the manuscript in ensuring that questions related to the accuracy or integrity of any part of it are appropriately investigated and resolved.

\section{Competing interests}

The authors declare that they have no competing interests.

\section{Consent for publication}

Not applicable.

\section{Ethics approval and consent to participate}

This study complied with the Declaration of Helsinki and was approved by the Norwegian Data Inspectorate and the Regional Committee for Medical and Health Research Ethics of North Norway. All subjects provided written consent.

\section{Author details}

'Metabolic and Renal Research Group, UiT The Arctic University of Norway, Tromsø, Norway. ${ }^{2}$ Department of Community Medicine, Faculty of Health Sciences, UiT The Arctic University of Norway, Tromsø, Norway. ${ }^{3}$ Section of Nephrology, University Hospital of North Norway, Tromsø 9038, Norway. ${ }^{4}$ Section of Nephrology, Department of Transplant Medicine, Oslo University Hospital, Rikshospitalet, Norway.

Received: 1 December 2016 Accepted: 24 February 2017

Published online: 28 February 2017

\section{References}

1. Klag MJ, Whelton PK, Randall BL, Neaton JD, Brancati FL, Ford CE, Shulman NB, Stamler J. Blood pressure and end-stage renal disease in men. N Engl J Med. 1996:334(1):13-8

2. Hsu CY, McCulloch CE, Darbinian J, Go AS, Iribarren C. Elevated blood pressure and risk of end-stage renal disease in subjects without baseline kidney disease. Arch Intern Med. 2005;165(8):923-8.

3. Haroun MK, Jaar BG, Hoffman SC, Comstock GW, Klag MJ, Coresh J. Risk factors for chronic kidney disease: a prospective study of 23,534 men and women in Washington County, Maryland. J Am Soc Nephrol. 2003;14(11):2934-41

4. Munkhaugen J, Lydersen S, Wideroe TE, Hallan S. Prehypertension, obesity, and risk of kidney disease: 20-year follow-up of the HUNT I study in Norway. Am J Kidney Dis. 2009;54(4):638-46.

5. Bash LD, Astor BC, Coresh J. Risk of incident ESRD: a comprehensive look at cardiovascular risk factors and 17 years of follow-up in the Atherosclerosis Risk in Communities (ARIC) study. Am J Kidney Dis. 2010;55(1):31-41.

6. United States Renal Data System. 2014 annual data report: epidemiology of kidney disease in the United States. Bethesda: National Institutes of Health, National Institute of Diabetes and Digestive and Kidney Diseases; 2014.

7. O'Hare AM, Bertenthal D, Covinsky KE, Landefeld CS, Sen S, Mehta K Steinman MA, Borzecki A, Walter LC. Mortality risk stratification in chronic kidney disease: one size for all ages? J Am Soc Nephrol. 2006;17(3):846-53.

8. Kronborg J, Solbu M, Njolstad I, Toft I, Eriksen BO, Jenssen T. Predictors of change in estimated GFR: a population-based 7-year follow-up from the Tromso study. Nephrol Dial Transplant. 2008;23(9):2818-26.
9. Halbesma N, Jansen DF, Stolk RP, De Jong PE, Gansevoort RT, for the PREVEND Study Group. Changes in renal risk factors versus renal function outcome during follow-up in a population-based cohort study. Nephrol Dial Transplant. 2010;25(6):1846-53.

10. Rifkin DE, Katz R, Chonchol M, Shlipak MG, Sarnak MJ, Fried LF, Newman AB, Siscovick DS, Peralta CA. Blood pressure components and decline in kidney function in community-living older adults: the Cardiovascular Health Study. Am J Hypertens. 2013;26(8):1037-44.

11. Hirayama A, Konta T, Kamei K, Suzuki K, Ichikawa K, Fujimoto S, Iseki K, Moriyama T, Yamagata K, Tsuruya K, et al. Blood pressure, Proteinuria, and renal function decline: associations in a large community-based population. Am J Hypertens. 2015;28(9):1150-6.

12. Wang Q, Xie D, Xu X, Qin X, Tang G, Wang B, Wang Y, Hou F, Xu X, Wang X Blood pressure and renal function decline: a 7-year prospective cohort study in middle-aged rural Chinese men and women. J Hypertens. 2015;33(1):136-43.

13. Peralta CA, Jacobs Jr DR, Katz R, Ix JH, Madero M, Duprez DA, Sarnak MJ, Criqui $\mathrm{MH}$, Kramer HJ, Palmas W, et al. Association of pulse pressure, arterial elasticity, and endothelial function with kidney function decline among adults with estimated GFR $>60 \mathrm{~mL} / \mathrm{min} / 1.73 \mathrm{~m}(2)$ : the Multi-Ethnic Study of Atherosclerosis (MESA). Am J Kidney Dis. 2012;59(1):41-9.

14. Lindeman RD, Tobin JD, Shock NW. Association between blood pressure and the rate of decline in renal function with age. Kidney Int 1984;26(6):861-8

15. Palatini P, Dorigatti F, Saladini F, Benetti E, Mos L, Mazzer A, Zanata G, Garavelli G, Casiglia E. Factors associated with glomerular hyperfiltration in the early stage of hypertension. Am J Hypertens. 2012;25(9):1011-6.

16. Harrap SB, Cumming AD, Davies DL, Foy CJ, Fraser R, Kamitani A, Connor JM, Lever AF, Watt GC. Glomerular hyperfiltration, high renin, and low- extracellular volume in high blood pressure. Hypertension. 2000;35(4):952-7.

17. Kotchen TA, Piering AW, Cowley AW, Grim CE, Gaudet D, Hamet P, Kaldunski ML, Kotchen JM, Roman RJ. Glomerular hyperfiltration in hypertensive African Americans. Hypertension. 2000;35(3):822-6.

18. Mimran A, Ribstein J, DuCailar G, Halimi JM. Hyperfiltration in lean essential hypertension. Contrib Nephrol. 1996;119:98-102.

19. Okada R, Yasuda Y, Tsushita K, Wakai K, Hamajima N, Matsuo S. Glomerular hyperfiltration in prediabetes and prehypertension. Nephrol Dial Transplant. 2012;27(5):1821-5.

20. Schmieder RE, Veelken R, Gatzka CD, Ruddel H, Schachinger H. Predictors for hypertensive nephropathy - results of a 6-year follow-up-study in essential-hypertension. J Hypertens. 1995;13(3):357-65.

21. Xie X, Atkins E, Lv J, Bennett A, Neal B, Ninomiya T, Woodward M, MacMahon S, Turnbull F, Hillis GS, et al. Effects of intensive blood pressure lowering on cardiovascular and renal outcomes: updated systematic review and meta-analysis. Lancet. 2016:387(10017):435-43.

22. Hsu CY. Does treatment of non-malignant hypertension reduce the incidence of renal dysfunction? A meta-analysis of 10 randomised, controlled trials. J Hum Hypertens. 2001;15(2):99-106.

23. Daien V, Duny Y, Ribstein J, du Cailar G, Mimran A, Villain M, Daures JP, Fesler $P$. Treatment of hypertension with renin-angiotensin system inhibitors and renal dysfunction: a systematic review and meta-analysis. Am J Hypertens. 2012;25(1):126-32.

24. The SPRINT Research Group. A randomized trial of intensive versus standard blood-pressure control. N Engl J Med. 2015;373(22):2103-16.

25. Peralta CA, McClure LA, Scherzer $R$, Odden MC, White CL, Shlipak $M$ Benavente O, Pergola P. Effect of intensive versus usual blood pressure control on kidney function among individuals with prior lacunar stroke: a post Hoc analysis of the secondary prevention of Small Subcortical Strokes (SPS3) randomized trial. Circulation. 2016:133(6):584-91.

26. Rule AD, Bailey KR, Lieske JC, Peyser PA, Turner ST. Estimating the glomerular filtration rate from serum creatinine is better than from cystatin C for evaluating risk factors associated with chronic kidney disease. Kidney Int. 2013;83:1169-76

27. Mathisen UD, Melsom T, Ingebretsen OC, Jenssen TG, Niølstad I, Solbu MD, Toft I, Eriksen BO. Estimated GFR is associated with cardiovascular risk factors independently of measured GFR. J Am Soc Nephrol. 2011;22(5):927-37.

28. Knight EL, Verhave JC, Spiegelman D, Hillege HL, de Zeeuw D, Curhan GC de Jong PE. Factors influencing serum cystatin $C$ levels other than renal function and the impact on renal function measurement. Kidney Int. 2004;65(4):1416-21. 
29. Soveri I, Berg UB, Björk J, Elinder C-G, Grubb A, Mejare I, Sterner G, Bäck S-E. Measuring GFR: a systematic review. Am J Kidney Dis. 2014;64(3):411-24.

30. Eriksen BO, Stefansson VT, Jenssen TG, Mathisen UD, Schei J, Solbu MD, Wilsgaard T, Melsom T. Elevated blood pressure is not associated with accelerated glomerular filtration rate decline in the general non-diabetic middle-aged population. Kidney Int. 2016;90(2):404-10.

31. Eriksen BO, Mathisen UD, Melsom T, Ingebretsen OC, Jenssen TG, Njølstad I, Solbu M, Toft I. Cystatin C is not a better estimator of GFR than plasma creatinine in the general population. Kidney Int. 2010;78(12):1305-11.

32. Singer JD, Willett JB. Applied longitudinal data analysis. Modelling change and event occurrence. Oxford: Oxford University Press, Inc.; 2003.

33. Rydstrom M, Tengstrom B, Cederquist I, AhImen J. Measurement of glomerular filtration rate by single-injection, single-sample techniques, using 51Cr-EDTA or iohexol. Scand J Urol Nephrol. 1995;29(2):135-9.

34. Brandstrom E, Grzegorczyk A, Jacobsson L, Friberg P, Lindahl A, Aurell M. GFR measurement with iohexol and 51Cr-EDTA. A comparison of the two favoured GFR markers in Europe. Nephrol Dial Transplant. 1998;13(5):1176-82.

35. Eriksson CG, Kallner A. Glomerular filtration rate: a comparison between Cr-EDTA clearance and a single sample technique with a non-ionic contrast agent. Clin Biochem. 1991;24(3):261-4.

36. Stevens LA, Levey AS. Measured GFR as a confirmatory test for estimated GFR. J Am Soc Nephrol. 2009;20(11):2305-13.

37. Mathisen UD, Melsom T, Ingebretsen OC, Jenssen TG, Njolstad I, Solbu MD, Toft I, Eriksen BO. Ambulatory blood pressure is associated with measured glomerular filtration rate in the general middle-aged population. J Hypertens. 2012;30(3):497-504

38. Solbu MD, Kronborg J, Eriksen BO, Jenssen TG, Toft I. Cardiovascular risk-factors predict progression of urinary albumin-excretion in a general, non-diabetic population: a gender-specific follow-up study. Atherosclerosis. 2008;201(2):398-406.

39. Eriksen BO, Lochen ML, Arntzen KA, Bertelsen G, Winther Eilertsen BA, von Hanno T, Herder M, Jenssen TG, Mathisen UD, Melsom T, et al. Estimated and measured GFR associate differently with retinal vasculopathy in the general population. Nephron. 2015;131(3):175-84

40. Inker LA, Schmid CH, Tighiouart H, Eckfeldt JH, Feldman HI, Greene T, Kusek JW, Manzi J, Van LF, Zhang YL, et al. Estimating glomerular filtration rate from serum creatinine and cystatin C. N Engl J Med. 2012;367(1):20-9.

41. Leffondre K, Boucquemont J, Tripepi G, Stel VS, Heinze G, Dunkler D. Analysis of risk factors associated with renal function trajectory over time: a comparison of different statistical approaches. Nephrol Dial Transplant 2014;30(8):1237-43.

42. Twisk J, de Boer M, de Vente W, Heymans M. Multiple imputation of missing values was not necessary before performing a longitudinal mixed-model analysis. J Clin Epidemiol. 2013;66(9):1022-8.

43. Royston P, Sauerbrei W. Multivariable model-building. Chichester: John Wiley \& Sons Ltd.; 2008.

44. Palmer BF. Renal dysfunction complicating the treatment of hypertension. N Engl J Med. 2002;347(16):1256-61.

45. Christensen PK, Akram K, Konig KB, Parving HH. Autoregulation of glomerular filtration rate in patients with type 2 diabetes during isradipine therapy. Diabetes Care. 2003;26(1):156-62.

46. Klahr S, Levey AS, Beck GJ, Caggiula AW, Hunsicker L, Kusek JW, Striker G. The effects of dietary protein restriction and blood-pressure control on the progression of chronic renal disease. Modification of Diet in Renal Disease Study Group. N Engl J Med. 1994;330(13):877-84.

47. Wright Jr JT, Bakris G, Greene T, et al. Effect of blood pressure lowering and antihypertensive drug class on progression of hypertensive kidney disease: Results from the AASK trial. JAMA. 2002;288(19):2421-31.

48. Bakris GL, Weir MR. Angiotensin-converting enzyme inhibitor-associated elevations in serum creatinine: is this a cause for concern? Arch Intern Med. 2000;160(5):685-93.

49. Brenner BM, Lawler EV, Mackenzie HS. The hyperfiltration theory: a paradigm shift in nephrology. Kidney Int. 1996;49(6):1774-7.

50. Perneger TV, Nieto FJ, Whelton PK, Klag MJ, Comstock GW, Szklo M. A prospective study of blood pressure and serum creatinine. Results from the 'Clue' Study and the ARIC Study. JAMA. 1993;269(4):488-93.

51. Vupputuri S, Batuman V, Muntner P, Bazzano LA, Lefante JJ, Whelton PK, He J. Effect of blood pressure on early decline in kidney function among hypertensive men. Hypertension. 2003;42(6):1144-9.
52. Schaeffner ES, Kurth T, Bowman TS, Gelber RP, Gaziano JM. Blood pressure measures and risk of chronic kidney disease in men. Nephrol Dial Transplant. 2008;23(4):1246-51.

53. Fox CS, Larson MG, Leip EP, Culleton B, Wilson PWF, Levy D. Predictors of New-onset kidney disease in a community-based population. JAMA. 2004;291(7):844-50.

54. Kanno A, Kikuya M, Asayama K, Satoh M, Inoue R, Hosaka M, Metoki H, Obara T, Hoshi H, Totsune K, et al. Night-time blood pressure is associated with the development of chronic kidney disease in a general population: the Ohasama Study. J Hypertens. 2013;31(12):2410-7.

55. Yamagata K, Ishida K, Sairenchi T, Takahashi H, Ohba S, Shiigai T, Narita M, Koyama A. Risk factors for chronic kidney disease in a community-based population: a 10-year follow-up study. Kidney Int. 2007;71(2):159-66.

56. Obermayr RP, Temml C, Knechtelsdorfer M, Gutjahr G, Kletzmayr J, Heiss S, Ponholzer A, Madersbacher S, Oberbauer R, Klauser-Braun R. Predictors of new-onset decline in kidney function in a general middle-european population. Nephrol Dial Transplant. 2008;23(4):1265-73.

57. Garofalo C, Borrelli S, Pacilio M, Minutolo R, Chiodini P, De Nicola L, Conte G. Hypertension and prehypertension and prediction of development of decreased estimated GFR in the general population: a meta-analysis of cohort studies. Am J Kidney Dis. 2016;67(1):89-97.

58. Keller G, Zimmer G, Mall G, Ritz E, Amann K. Nephron number in patients with primary hypertension. N Engl J Med. 2003;348(2):101-8.

59. Elsherbiny HE, Alexander MP, Kremers WK, Park WD, Poggio ED, Prieto M, Lieske JC, Rule AD. Nephron hypertrophy and glomerulosclerosis and their association with kidney function and risk factors among living kidney donors. Clin J Am Soc Nephrol. 2014;9(11):1892-902.

60. Lenihan CR, Busque S, Derby G, Blouch K, Myers BD, Tan JC. The association of predonation hypertension with glomerular function and number in older living kidney donors. J Am Soc Nephrol. 2015;26(6):1261-7.

61. Boucquemont J, Heinze G, Jager K, Oberbauer R, Leffondre K. Regression methods for investigating risk factors of chronic kidney disease outcomes: the state of the art. BMC Nephrol. 2014;15(1):45.

62. Johnson RJ, Lanaspa MA, Gabriela Sanchez-Lozada L, Rodriguez-Iturbe B. The discovery of hypertension: evolving views on the role of the kidneys, and current hot topics. Am J Physiol Renal Physiol. 2015;308(3):F167-78.

\section{Submit your next manuscript to BioMed Central and we will help you at every step:}

- We accept pre-submission inquiries

- Our selector tool helps you to find the most relevant journal

- We provide round the clock customer support

- Convenient online submission

- Thorough peer review

- Inclusion in PubMed and all major indexing services

- Maximum visibility for your research

Submit your manuscript at www.biomedcentral.com/submit 